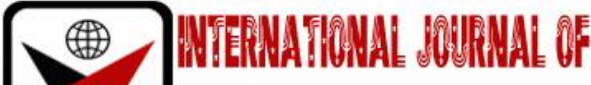

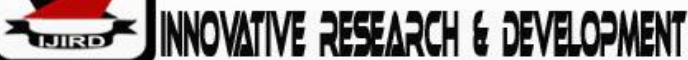

ISSN 2278 - 0211 (Online)

\section{Dress Features Suitable for Provision of Smart Maternity Wear}

\author{
Nelima Barasa \\ Assistant Lecturer, Department of Physical Science, Rongo University, Kenya
}

\begin{abstract}
:
Smart maternity wear is a garment used during pregnancy and designed with an aim of accommodating the physical body changes in a healthy and fashionable way. Smart maternity wear is designed with features that meet the performance requirement of the pregnant woman in a healthy way. The normal maternity wear has been designed in a way that they accommodate the physical features during pregnancy without considering the final look of the expectant woman. Most of the expectant women have complained that such garment has left them looking big and shaggy. The aim of this study was to establish the dress features suitable for smart maternity wear that caters for the health of the fetus and the mother. Data was collected by questionnaire and interview schedule applied on 96 pregnant women, attending antenatal clinics at Kenyatta national hospital, Kenya. The obtained data was analyzed in relation to the themes created from the results. The results indicated that most expectant women said that dress features like color, fit and appearance of the maternity wear were suitable for their maternity wear as it gave them an adorable look.
\end{abstract}

Keywords: Dress features, smart maternity wear, pregnancy, trimester

\section{Introduction}

Pregnancy period is a time when women experience dramatic changes in their physical body [Ogle, 2013]. This as a result leads to the need of maternity wear that will accommodate these changes [Noopur, 2012]. Smart maternity wear is a garment used during pregnancy and designed with an aim of accommodating the physical body changes in a healthy and fashionable way. These dress features should accommodate the changes in the body weight, silhouette and posture and also give a pregnant woman a healthy and smart look [Barasa 2016]. The design of maternity wear should not only accommodate the personal physical changes, but also provide comfort, aesthetic value and proper sizing and fit [Shang and $\mathrm{Hu}$ 2015]. Therefore, clothes for pregnant women should be not only beautiful but also convenient and comfortable because what a lady wears during pregnancy has a profound effect on her health [Arya, Singh and Khambra, 2014].

Maternity wear has grown massively in recent years creating an extensive choice of trendy maternity wear from which expectant women can select from (Faust \& Carrier, 2014).Women during pregnancy put forward higher demand on clothing in comfort level, security as well as aesthetic measure because of their strong secretion of hormone and special need for mentality, physiology and physical characteristic (Shang and Hu, 2015).Due to the rapid growth in technology, designers and manufacturers have come up with maternity wear in different cutline and fabrics [Sohn and Bye 2015]. There is improvement in the fabric qualities that are also friendly to the pregnant body and the fetus. Aishatu (2011) advised that maternity designing should be guided by the basic design principles that apply to the selection of the pregnant women's wardrobe. These principles will lead to the maternity wear to acquire some features which most pregnant women will be looking for during the selection [Barasa 2016]

During pregnancy, the shape and size of the body changes due to the increase in the size of the abdomen and bust area of the pregnant women [Georgeta, Alexandra \& Sabina, 2014]. This also lead to change in the body posture since the body is trying to create a balance in the spinal area due to the increased weight in the abdomen [Sohn and Bye 2015].To accommodate the body silhouette, the pregnant woman needs the best maternity clothes that will clothe her till the end of third trimester. The typical maternity clothes should tone down the weight gained and at the same time be comfortable [Arya et al, 2014]. They should also be worn during and after pregnancy [Noopur, 2012].

\subsection{Key Dress Features for Provision of Smart Maternity Wear}

\subsubsection{Fabric}

Nowadays, maternity dress design demand for high concentration on the type of material and it's properties, such as comfort and functionality [Shang and Hu 2015]. The material which is friendly to the body, absorbent and can prevent body radiation will be preferred for pregnant women. Natural fabric that is stretchy and light in weight provides the necessary comfort and functionality of maternity wear [Sujata 2010]. Patterned fabrics help conceal the silhouette of a pregnant body thus giving the pregnant woman a body shape that is adorable [Aishatu 2011]. In addition, plaids, checks, 
and other prints help conceal the silhouette of pregnant women and add interest to the maternity clothes if they are well used. Ideally, fabrics for maternity wear should be neither too stiff nor too soft, neither too heavy nor too flimsy, but have sufficient body to hold their shape. Weber (1990) stated that cotton materials help create balance in body heat transmission thus making a pregnant woman to feel comfortable. More so, since pregnant women feel hot during pregnancy, cotton materials are the best for the construction of maternity garments that will make pregnant women comfortable during hot climate (Faust and Carrier, 2014).

Shimmering textures reflect light thereby making the figure appear larger and revealing its shape (Sujata, 2010). Dull and bulky textures create shadows thus making the expectant woman's body appear big (Weiss, 2013). Aishatu (2011) highlights that these textures are usually considered un desirable for maternity wear, because they too increase the size of the wearer.

\subsubsection{Design}

The design of the maternity wear has to be carefully selected so that it suits the wearer (Aishatu 2011). Design details like pleats and gathers on maternity wear create different effects on the body (Aishatu, 2011). If not well selected they can exaggerate the figure in terms of body size and shape. These features also give proper fit of the maternity wear as they try to accommodate the physical changes that occur during pregnancy (Sohn, 2009). Too many cut lines on maternity wear distorts the body silhouette during pregnancy. It's therefore advisable to reduce the number of cut lines and at the same time maintain the style of the maternity wear in order to make it smart.

\subsubsection{Sizing and Fit}

Due to the body changes that take place during pregnancy, expectant women need maternity wear that is of proper size, fit and comfort (Komarkova and Musilova, 2010). In a study undertaken by Sohn (2013), she found that pregnant women first begin to show significant changes in body shape and size beginning in their fifth month of pregnancy. The difficulties experienced during pregnancies can be avoided by wearing maternity wear that is of the required size (Sujata, 2010). Improper sizing and fit of maternity wear affect the health of the fetus and mother thus making them uncomfortable. On the other hand, maternity wear that does not fit the pregnant body well affects the look of the pregnant women in a negative way.

\subsubsection{Colour}

Colours play a big role of setting the mood of the day and sculpturing the shape of an expectant woman's body (Sujata, 2010). Since the expectant woman is no longer subjected to colour restrictions, she has free rein in the selection of colours for her wardrobe. However, she should not deviate radically from her normal colour preferences. Personal colouring, figure type and size of wardrobe should be the determining factors. Some women prefer more conservative dress colours as a background for colourful accessories. The size of the maternity wardrobe will limit the variety of colour that may be used. It should also be remembered that figure size is affected by colour. Light colour tends to make one seem larger while dark colours will have a slimming effect on the eye (Weiss, 2013).

\section{Material and Method}

The target population for this study was drawn from expectant women attending ante-natal clinic at the reproductive health department, Kenyatta National Hospital. Convenience method of sampling was used to select 90 respondents (30 from each trimester) who participated in the study. The researcher met with the nurse on duty prior to the recruitment process to explain the purpose of the study. With prior arrangement with the nurse on duty, the researcher explained to each selected young expectant woman the purpose of the study after which an interview was conducted and questionnaires filled. This enabled the researcher to collect data from expectant women in the first trimester, then second and finally third. To make the respondents more comfortable the researcher motivated them through good communication and maintained good rapport.

\section{Results}

To establish the dress features suitable for provision of smart maternity wear, the various dress features were highlighted. The expectant women were then asked to state using a bi-polar scale the dress features that they would find suitable for smart maternity wear. The results of the respondents were as shown in figure1. 


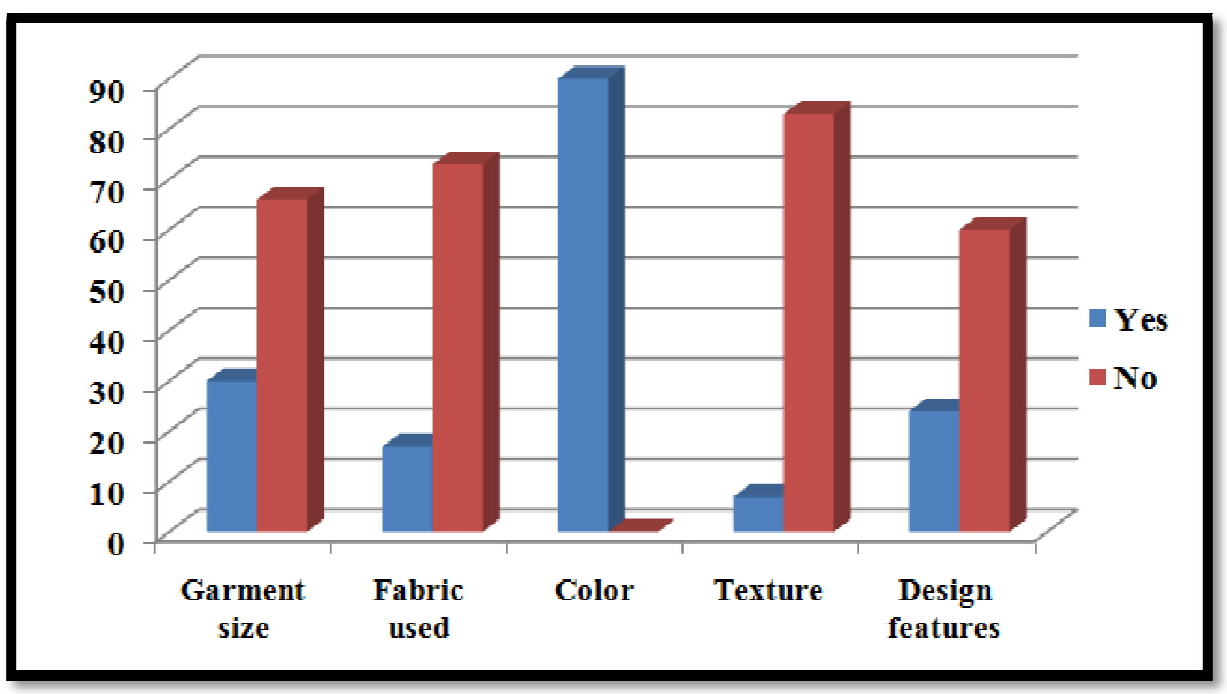

Figure 1: Dress Features Suitable for Designing Smart Maternity Wear

The results in Figure1indicate that colour of the maternity wear was considered as the outstanding dress feature suitable for provision of smart maternity wear. All the respondents were influenced by colour in selecting maternity wear. This was attributed to the respondent's desire to go for colours they liked most without putting in mind that the effect of colour on their body size and shape.

Garment size was the second dress feature that was considered suitable for smart maternity wear. This accounted for 30 respondents. This was attributed to the expectant women's need to select maternity wear that could accommodate the changes in their body shape and size thus making them comfortable and fashionable.

Design features were also considered suitable for smart maternity wear. It accounted for 24 respondents. This was attributed to the increase in dramatic body changes that generated the need for maternity wear for the expectant women. In addition, the expectant women indicated that the design features would camouflage their body shape thus making them fashionable.

Fabric used to make the maternity wear was also considered by less than 20 respondents to be suitable for smart maternity wear. This was attributed to the fact that different fabric has an impact on their look during pregnancy.

Texture was considered by 7 young expectant women as a dress feature for provision of smart maternity wear. The respondents stated that they liked maternity wear with patterns so as to hide their protruding abdomen.

\section{Discussion}

Smart maternity wear provides an alternative to expectant women who would want to have a healthy pregnancy and at the same time look fashionable. Research has indicated a difference in the occurrence of the physical body changes among the expectant women due to Body Mass Index (BMI). This has led to a difference in body sizes and shape among expectant women during pregnancy. Dress features like colour, fabric, sizing, design and texture found on smart maternity wear will offer comfort and aesthetic value of maternity wear. In addition, expectant women will look more fashionable if the dress features are selected properly in relation to body size and shape.

\section{Conclusions and Recommendations}

Based on the finding, dress features are virtual components in any attempt to select a garment that will function well on the body of any human being. Smart maternity wear will not only accommodate the body changes during pregnancy but will also offer a pregnant woman healthy- and good-looking properties. This will give them a good-looking figure that is not ill fitting and shaggy. The study recommends the need for the health sector and fashion designers to educate the expectant women on the use of smart maternity wear during pregnancy.

\section{References}

i. Aishatu, S. M. (2011). Acceptability of Designed and Constructed Maternity Wear for Pregnant Women in Niger State, Department of Vocational and Technical Education. Niger State: Unpublished. Retrieved on 4 April, 2013 from www.ncbi.nlm.nih.gov.

ii. Arya, N., Singh, V., \& Khambra, K. (2014). Paper Pattern of Designer Kameez for Rural Expectan Women. Asian Resonance, pp. 226-229.

iii. Barasa, N. (2016). Views of Young Expectant Women on Physical and Psychological changes and their influence on Maternity Wear Selection, Department of Fashion Design and Marketing: Kenyatta University. www.ku.ac.ke.

iv. Faust, M. E.\& Carrier, S. (2014). Apparel for Consumers: The Impact of Body Shape and Size. Wood head Publishing Limited. Retrieved on 9 March, 2015 from www.amazon.com.

v. Georgeta, P., Alexandra, M., \&Sabina, O. (2012). Innovative Clothing Design for Women during Pregnancy. Annals of the University of Oradea Fascide of Textile, Leatherwork., PP. 221-226. 
vi. Komarkova, P.\& Musilova, B. (2010). Pattern Construction of Maternity Wear. 7th International Conference TEXSCI (pg. 1-2). Liberec, Czech Republic: Technical University of Liberec. Retrieved on 24 June, 2013 from www.wjoehebeu.edu.cn/sup.

vii. Noopur, A. (2012). Smart Maternity Wear-an answer to Longetivity Problem of Maternity. Journal of Textile and Apparel,Technology and Management. , PP 1-3. Retrieved on 30 Aprill, 2013 from www.ojs.cnr.ncsu.edu.

viii. Ogle, J.P., Tyner, K.E, \& Tomschin, S.S (2013). The role of Maternity Dress Consumption in Shaping the Self and Identity during the Liminal Transition of Pregnancy. Journal of Consumer Culture, pp. 119-139.

ix. Shang, Y., \& Hu, X. (2015). Ergonomic Maternity Dress Design. PP. (187-191). Guangzhou: Elsevier B.V.

x. Sohn, M. (2009). A Pattern Adaptation for Body Changes during Pregnancy. A Single Case Study. A Thesis Submitted to the Faculty of the Graduate School of the University of Minnesota, PP 1-5. Unpublished. Retrieved on 24 January, 2013 from http://www.conservancy.umn.edu.

xi. Sohn, M. (2013). Designing Maternity Wear for Expectant Women. Retrieved 31 October, 2013, from www.medicalxpress.com.

xii. Sohn, M., \& Bye, E. (2015). Pregnancy and Body Image: Analysis of Clothing Functions of Maternity Wear. Clothing and Textiles Research Journal, pp. 64-78.

xiii. Sujata, O. (2010). Maternity wear. Retrieved 5 November, 2013 from www.glamcheck.com.

xiv. Weber, J. (1990). Clothing Fashion and Fabric Construction (2nd edition). New York: McGraw hill. Retrieved on 24 June, 2013from www.amazon.co.uk.

xv. Weiss, R. E. (2013).Pregnancy as a Journey. Retrieved 5 November, 2013, fromwww.pregnancy.about.com. 